


\title{
Análisis preliminar del gobierno universitario chileno
}

\author{
Ganga Contreras, Francisco A.*
}

\section{Resumen}

Es axiomático que los megacambios que se suceden hoy en día en el mundo, han influido en la forma como las organizaciones deben ser gestionadas. Esta situación ha afectado a las universidades, desprendiéndose que existen espacios relevantes para repensarlas en todas sus dimensiones, y la gestión es quizás una de las más vitales, dado que se constituye en el eje vertebrador de los objetivos de cualquier institución. El presente trabajo pretende proporcionar información de reconocimiento del problema del gobierno universitario, considerando a tres universidades regionales y amparado con fundamento en la teoría sobre el gobierno corporativo y el enfoque de agencia. Se busca identificar la percepción de las autoridades, respecto a la eficiencia del gobierno en las universidades chilenas y del entorno de la cual son parte; y además, analizar la relación de agencia que se da entre los rectores y su máximo cuerpo colegiado. Los resultados revelan: asimetrías de información, divergencias en cuanto a intereses y mecanismos alineadores entre los rectores y su máximo cuerpo colegiado y coincidencia sobre la eficiencia y las bondades del control. Se concluye sobre la necesidad de ampliar este tipo de investigación con miras al mejoramiento de las relaciones entre los rectores y el máximo cuerpo colegiado.

Palabras clave: Gobierno corporativo, principal, agente, universidades.

\section{Preliminary Analysis of University Management in Chile}

\section{Abstract}

It is axiomatic that mega-changes occurring in the modern world have influenced the manner in which organizations should be managed. This situation has affected universities, with the understanding that there is relevant space in which to re-think all the dimensions of these institutions, as

\section{Recibido: 04-09-25. Aceptado: 05-03-30}

Administrador Público, Magíster en Administración de Empresas, DEA en Organización de Empresas, Dr @ e en Nuevas Tendencias en Dirección de Empresas. Académico de la UNIVERSIDAD DE LOS LAGOS. Correo postal: Serena 77, Universidad de Los Lagos, Puerto Montt, Chile.E-mail: fganga@ulagos.cl 
well as the management of the same which is even more vital, since it constitutes the structural ordering of the objectives of any institution. This paper attempts to offer recognition of the problem of university government, taking into consideration three regional universities, and based on the theory of corporative government and the agency focus. The perception of the university authorities in relation to the efficiency of Chilean university government is identified, as well as the environment of which it forms a part, and an analysis of the agency relationship that exists among the rectors and the principal collegiate bodies. The results reveal informational asymetry, divergence in relation to interest and alignment mechanisms among the rectors and the collegiate body, and coincidence in relation to efficiency and the need for control. The conclusion related to the need to pursue this type of research, is that there is a need to better relations among rectors and the maximum collegial bodies.

Key words: Corporative government, principal, agent, university.

\section{Introducción}

Las universidades, como instancias de irradiación de vida intelectual, juegan un papel de especial trascendencia en la vida de las personas, pues, son probablemente una de las vías más efectivas para lograr el desarrollo, profundización y administración de conocimientos, tan necesarios para el mejoramiento del bienestar de la sociedad que las cobija. Es por ello que requieren de una apropiada dirección, para poder cumplir con niveles de eficiencia el rol a que para el cual han sido creados.

En Chile, desde diversas instancias, han emergido una gran variedad de críticas respecto de la forma como está operando el sistema universitario chileno, especialmente en lo referente a la manera como son gestionadas. El ministerio de educación de este país, ha reconocido que es urgente mejorar la calidad de la educación superior y ha puesto en marcha el denominado Programa de Mejoramiento de la Calidad de la Educación Superior (MECESUP).

De lo anterior se desprende que existe la necesidad de repensar las uni- versidades en todas sus dimensiones, y en este orden de cosas, la teoría sobre gobierno corporativo y el enfoque de agencia, se constituyen en fundamentos teóricos consistentes para analizar desde una óptica estructural y gubernamental este tipo de organizaciones.

La idea de este trabajo es trazar cimientos teóricos que nos posibiliten encadenar por un lado, la realidad de las universidades chilenas y, por otro, la teoría del gobierno de las organizaciones, desde la perspectiva de la teoría de agencia.

En concreto, se busca lograr los siguientes propósitos: Determinar el nivel de existencia de asimetrías informativas entre los miembros de los MCC y los rectores, de las universidades chilenas analizadas, analizar las posibles divergencias entre los intereses de los "principales" de las universidades chilenas y sus directivos superiores, evaluar la percepción por parte de los participantes, del nivel de eficiencia del gobierno universitario, estudiar la percepción de los participantes, respecto de los principales mecanismos alineadores de intereses existentes en las universidades chilenas, analizar los mecanismos de control interno y 
externo, que se utilizan en las universidades chilenas, para atenuar los problemas de agencia entre los MCC y los directivos superiores, determinar la perspectiva y la posición de los participantes respecto de la legislación y sus efectos en la eficiencia en la gestión de las universidades chilenas.

Es preciso advertir al lector, que como análisis exploratorio, los resultados obtenidos deben ser considerados como preliminares del problema de agencia en el gobierno universitario chileno, sin embargo, también se debe reconocer, que gracias a esta indagación primaria, se han sentado las bases que justifican una eventual investigación en todo el sistema universitario chileno.

En cuanto al proceso de recopilación de información, básicamente se utilizan fuentes de información primaria, dado que se ha intentado obtener información directamente de las universidades seleccionadas para el estudio. Pero además se utilizaron fuentes de información secundarias, referenciados principalmente por revisiones bibliográficas que abordan el problema de la gestión universitaria y los temas de la teoría de agencia y gobiernos corporativos.

La técnica utilizada para recoger la información, fue una encuesta directa (cuestionario/encuesta), que se aplicó a los rectores de las universidades seleccionadas y a los integrantes de sus respectivos cuerpos colegiados superiores, todos fueron encuestados presencialmente por el investigador. Las variables fueron medidas a través de una batería de preguntas, que corresponden en su mayoría, a aquellas con respuesta a "escala" (escala de Likert) y en menor proporción a preguntas "dicotómicas" y del tipo "abiertas". La información recopilada fue procesada en el sofware estadístico SPSS, realizándose primordialmente análisis de frecuencia y tablas de frecuencia.

\section{Reflexiones sobre el gobierno corporativo y la teoría principal/agente}

Con la finalidad de establecer las bases teóricas que sustenten doctrinalmente el presente trabajo, se desarrollarán a continuación ideas relacionadas con el gobierno corporativo y la teoría de agencia.

\subsection{El gobierno de la empresa ${ }^{1}$}

La literatura sobre gobierno de la empresa es muy abundante, por lo que las definiciones de gobierno corporativo son cuantiosas. Una de las más interesantes es la de Shleifer y Vishny (1997) quienes afirman que el gobierno de las empresas tiene que ver con los medios a través de los cuales, quienes proporcionan fondos financieros se aseguran una retribución adecuada a sus inversiones.

Complementariamente, se puede indicar que el gobierno corporativo se vincula necesariamente con las políticas que regulan los derechos de los accionistas y las responsabilidades de los conse-

1 En este trabajo se entenderán como sinónimos los conceptos "gobierno de la empresa" o "gobierno corporativo". 
jos de administración, sin dejar de lado la relación de la empresa con la sociedad. (Maw et al., 1994; Bengoechea, 1996; Díaz, 2003; Parisi et al., 2000; Salas, 2002; Mathiesen, 2002; 1997; OECD, 1999). El gobierno corporativo está afectado por factores tanto endógenos como exógenos, los cuales deben interrelacionarse en un contexto donde no todos los participantes manejan en proporción equivalente la información disponible. En un análisis más detallado, existen autores que sostienen que la información sobre gobierno corporativo ha centrado tradicionalmente su atención en las relaciones contractuales entre aportantes de fondos (propietarios y acreedores) y dirección. El planteamiento que subyace bajo esta relación, es que una mayor eficacia en la supervisión y el control de la dirección, llevada a cabo a través de diferentes mecanismos de gobierno, supondrá una reducción de costes de agencia ${ }^{2}$ que, en definitiva, redundará en un mayor valor de la entidad (Azofra y Santamaría, 2002) Esta óptica analítica tiene bastante lógica, toda vez que en ella pueden incluirse aspectos tan esenciales como el papel que juegan los directivos como pieza central de las relaciones contractuales, como influye la estructura de propiedad en el control de las actuaciones directivas, como afecta el diseño de los órganos de gobierno a la supervisión y resolución de conflicto, o más recientemente, si es factible repartir los derechos de decisión y control entre diferentes participes dentro del consejo de administración
(Zingales y Rajan, 1998; Bengoechea, 1996; Berglöf, 1997; Escobar, 2001; Le Fort y Walker, 2001).

A pesar de lo enunciado, no se puede terminar este punto sin bosquejar cuáles son en definitiva los aspiraciones principales del gobierno corporativo. En la línea de Parisi et al (2001) y considerando las definiciones presentadas, es factible colegir que éste debe preocuparse de dos grandes propósitos a saber:

a) Proveer una estructura eficiente de incentivos a la dirección, por medio del diseño de mecanismos alineadores que permitan la concordancia de los fines organizacionales con los fines de los gestores o administradores. Esto posibilitará una contribución apropiada al proceso de incremento del valor de la empresa, en un horizonte temporal de largo plazo.

b) Fijar responsabilidades y otras salvaguardias que impidan que los directivos y accionistas controladores usen el control para extraer valor de ésta a expensas de los accionistas minoritarios. Este objetivo tiene una relevancia significativa, en aquellos casos de sociedades anónimas que son controladas por un solo accionista o grupo económico.

\section{- El "buen gobierno corporativo"}

Entendido el gobierno de la empresa como la relación que establece la compañía con sus accionistas, pero además con la sociedad en general; es válido en estas circunstancias, manifestar la necesidad de que los directivos se conduzcan 
bajo la observancia ineludible de la transparencia, la equidad corporativa y el cumplimiento de una serie de responsabilidades éticas al interior de la empresa. En otras palabras, el "buen gobierno corporativo", se materializa cuando éste puede impedir y/o solucionar los conflictos de intereses que surgen entre los administradores y los accionistas.

Dentro de este escenario analítico, un elemento que pudiese destacarse, se relaciona con la protección que debe brindársele al accionista minoritario, este amparo debe ser el producto de un "mix" de múltiples factores que guarezcan en forma eficiente y eficaz los derechos de propiedad que tienen los accionistas. Entre esta pluralidad de variables se podrían citar, por ejemplo; la normativa legal societaria, los normativas legales específicas (cuando se trate de fusiones, adquisiciones o reorganizaciones de empresas), reglamentos internos etc. Todos estos linderos o marcos regulatorios, no deben descuidar el esclarecimiento de un apropiado equilibrio entre la mayoría y las minorías, de forma tal, que se restringa al mínimo las factibilidades de abuso de los derechos que tienen los diversos participantes.

Adicionalmente, se debe reconocer que existe una basta literatura, acerca del "buen gobierno corporativo" de la cual se puede desprender que un régimen de esta naturaleza, debe ayudar a promover una utilización eficaz del capital de las empresas; estimular una buena relación entre los entes involucrados; fomentar la confianza, la transparencia y el respeto de los derechos de los accionistas; generar condiciones para que las empresas tomen en cuenta los intereses de un amplio rango de componentes, al igual que con la sociedad en la cual están insertos. Debe haber además nitidez en la definición de las responsabilidades y funciones del consejo de administración; fluidez, probidad e integridad de la información y; procesos comunicacionales efectivos con todos los "interesados" (De la Fuente, 2002; KPMG, 2002, 2003; OECDE, 1999).

\section{- Los consejos de administración}

En la mayoría de las empresas, el principal órgano de gobierno, lo constituye el consejo de administración (CA). En esta condición a los CA le corresponde constituirse en organismos de control y en factores que armonicen a los diversos colectivos que son habitualmente parte de una organización. Como rasgo peculiar, está el hecho de que los CA delegan en los directivos la administración de la empresa; pero para ello, deben aferrarse a los derechos de selección y retribución de directivos, además de la gestión estratégica de la organización. Es de suma relevancia considerar la probabilidad de que ocasional e imprevistamente los consejeros pueden enfilarse con los intereses de los directivos, pero, claramente es el mercado de consejeros el que sirve como mecanismo inhibidor de estas prácticas, dado que su capital humano y prestigio se verían afectados, en una práctica de esta naturaleza, aminorando su valor y las oportunidades de empleos en otros consejos de administración.

Considerando estas competencias y particularidades, los CA se convierten en los órganos disciplinarios de los altos 
directivos por delegación de los accionis$\operatorname{tas}^{3}$ quienes le transfieren la facultad y el poder de limitar, en el ejercicio de su labor supervisora, la discrecionalidad de los directivos. Su actuación influye directamente en el valor de la empresa, pues la amenaza ayuda a disciplinar a los directivos (Fernández y Gómez, 1999).

Pero en general, los códigos de gobierno corporativo establecen como principales funciones del consejo: la aprobación de la estrategia de la compañía; la identificación de riesgos, vulnerabilidades, amenazas y oportunidades para el futuro de la empresa; la supervisión del negocio; el control efectivo de la gestión; la participación activa en la selección, evaluación, remuneración, mantención, desarrollo y sucesión del director general y los de los directivos de más alto rango jerárquico y; la protección de los intereses de los accionistas y de otros interesados legítimos (Fundación de Estudios Financieros, 2002; Cuervo-Cazurra, 1996).

\subsection{El problema de agencia en las organizaciones}

Como se ha expresado, el gobierno de las empresas es un tema que ha preocupado a los diversos autores del ámbito económico y de organización de empresas, desde hace más de un siglo. Los problemas se podrían buscar en las antiguas compañías por acciones que eran una forma organizativa creada por los comerciantes británicos en el siglo XVIII. Estas compañías de naturaleza privada emitían acciones susceptibles de negociación por parte de sus propietarios, los cuales sin embargo no podían actuar en nombre de la compañía, pues el control de la misma era competencia exclusiva de sus managers (Azofra, 1999).

A partir de esas realidades, se han estudiado y analizado las complicaciones que emergen, producto de la separación entre la propiedad de la empresa y el control de ésta. El segundo factor (control), se encuentra en las grandes organizaciones a cargo de ejecutivos, quienes se enfrentan a la tentación de practicarlo a su favor, existiendo una multiplicidad de formas para hacerlo.

Dentro de este contexto, la perspectiva que mejor puede abordar esta problemática es la que viene del enfoque contractual o teoría de agencia, ya que lo desarrollado es un claro problema de agencia, donde el accionista inversor (que denominaremos principal), debe confiar la administración a un gestor, gerente o administrador (el que conoceremos como agente), con el cual tendrá claras asimetrías de información, intereses divergentes y funciones de utilidad dispares. Bajo este formato de análisis, el problema más relevante en el gobierno de la empresa, es la confección de normas e incentivos, contratos implícitos o explícitos, que alineen efectivamente el comportamiento de los agentes, directivos, con los deseos del principal, accionistas (Fernández y Gómez, 1999).

3 Son los accionistas quienes nombran a los consejeros, los cuales pueden ser internos y externos. Los primeros ocupan cargos directivos dentro de la empresa y los segundos no, lo cual le otorga tácitamente independencia y mayor nivel de objetividad. 
Este será el gran desafío que se deberá emprender con el modelo "principal-agente", y para ello es prioritario comenzar por comprender lo que involucra la teoría de agencia. En este contexto resulta ineludible referirnos a los profesores Michael Jensen y William Meckling (1976) quienes definen la relación de agencia como un contrato bajo cuyas cláusulas una o más personas (el principal) contratan a otras personas (el agente) para que realice determinado servicio en su nombre, lo que implica cierto grado de delegación de autoridad en el agente.

También se puede señalar, de manera complementaria, que la relación de principal/agente, opera en aquellas circunstancias donde un principal delega el control sobre algunos recursos a un individuo, que se le denomina agente, quien está obligado por un contrato formal o informal, a representar los intereses del delegador a cambio de algún tipo de retribución.

De los antecedentes proporcionados, se puede inferir que los principales deben enfrentar básicamente dos peligros al llevar a la praxis, el proceso de delegar autoridad y responsabilidad para tomar decisiones, en otros individuos: a) EI riesgo que debe enfrentar todo empresario (principal), cuando decide contratar administradores para su negocio. En estas circunstancias, existe la factibilidad de que el agente no se comporte como el principal desea y actúe, por lo tanto, encauzado según sus propios intereses ${ }^{4}$. b) El riesgo de que el agente contratado no sea lo suficientemente competente, es decir, que no tenga realmente las capacidades, intereses, habilidades y aptitudes requeridas, como para desempeñar en forma eficiente el cargo o la responsabilidad que se le ha entregado ${ }^{5}$.

\subsection{Características del enfoque de agencia}

Sintéticamente, y en el contexto de las características de este modelo, se sostiene que es factible distinguir por lo menos las siguientes.

En primer lugar se debe reconocer que existen claramente dos actores: los agentes (que pueden ser las "personas que están dentro de la organización", tales como, los directivos, ejecutivos, gerentes entre otros) y el principal (relacionadas con las "personas que están fuera de la organización", como es el caso de los inversionistas, clientes etc.); las relación que se gesta entre estos dos entes es producto de contratos celebrados oportunamente, es decir, son de naturaleza contractual ${ }^{6}$; en este vínculo el agente tiene una posición de subordinación, sujeción o dependencia del principal; las motivaciones de las partes son distintas, existiendo por lo tanto conflicto de intere-

4 Este proceso se conoce técnicamente como "riesgo moral", tema que es abordado más adelante.

5 Técnicamente se conoce este proceso como "selección adversa", tema que se aborda más adelante.

6 Esta es la razón por la cual la teoría de agencia se conoce también con el nombre alternativo de enfoque contractual. 
ses, por lo que están dispuestas a asumir diferentes niveles de riesgo. A su vez, se debe tener presente que el comportamiento del agente es determinante sólo en parte de los resultados, ya que se considera que el esfuerzo que realiza éste influye en los resultados o los beneficios que espera el principal, pero no en forma dominante, dado que ellos están dependiendo de las características del ambiente o entorno. Además se postula que los resultados deben ser perceptibles de manera objetiva por las partes involucradas. Otra de las cuestiones importantes que se plantean, es que bajo este enfoque se busca maximizar el beneficio esperado del principal, respetando las características de cada caso, pero incitando a que el agente tome las acciones que sean más óptimas, utilizando para ello sistemas de incentivos. Respecto de la información, también se debe destacar que ésta no es homogénea entre las partes.

Finalmente, se debe considerar que uno de los problemas del principal es que él no puede observar y supervigilar la acción del agente fácilmente o de manera perfecta, situación que lleva aparejado un coste que debiera ser razonable, si es que se quiere asegurar viabilidad de la organización (Martín y Gutiérrez, 2001; Arruñada, 1990 Suárez, 1997).

\subsection{Algunos problemas de agencia}

La hipótesis de partida de la teoría de agencia, sostiene relación con la existencia de la asimetría de información, la cual se ve expresada por múltiples razones, pero que evidentemente emergen cuando se realiza la delegación de la gestión en un agente, por parte del principal. En esta relación se manejan distintos ni- veles de información, dependiendo del rol que se esté ocupando. Es claro que el directivo, por encontrarse "dentro de la empresa" tiene mayor información que el principal, el que se ubica fuera de la empresa.

Esta problemática se agudiza en aquellos casos donde existe más de un agente en diferentes áreas, los cuales tienen que ser supervisados por el principal, lo que limita la posibilidad de mejorar la mayor cantidad de información que debe manejar de cada área. Si lo quisiera realizar, tendría que incurrir en diversos costos, por esto, en muchas entidades a los agentes se les pide un informe anual de su gestión, ya que si lo realizaran más seguido, esto provocaría al principal, incurrir en elevados costos de transmisión de información.

Estas asimetrías de información pueden darse en dos escenarios a saber: cuando existe asimetría ex-antes del contrato, se originan problemas de agencia, conocidos como "selección adversa"; y cuando esto ocurre ex-post del contrato, da lugar a problemas de agencia del tipo "riesgo moral". Ambas situaciones se abordan a continuación.

\section{- Selección adversa}

El problema de la selección adversa es, básicamente, el proceso de ocultamiento de información "ex ante" a la firma del contrato y, como es lógico, tiene efectos negativos en la relación contractual entre principal y agente. En este caso, el agente posee información privada sobre variables que afectan a la transacción y que el principal desconoce, pudiéndose citar como ejemplo, sus niveles de productividad. 
Es por ello, que éste es un problema de asimetría de información entre las dos partes involucradas, ya que se produce cuando existe un candidato dispuesto a ocupar un cargo dentro de la organización, el cual no entrega toda la información que es requerida por el principal. El origen de esta problemática ocurre cuando se realiza una mala elección del candidato, por carencia de información, y éste no se ajusta a los requerimientos del dueño de la empresa, llevando a la organización a tener perdidas de eficiencia (Pérez, 1997; Novy, 2004).

\section{- Riesgo moral}

Puede entenderse por "riesgo moral" al comportamiento del "agente" que es disímil a lo requerido por el "principal", cuando se celebró el respectivo contrato; teniendo como efecto primordial, el perjuicio de los intereses del "principal", esencialmente en escenarios inciertos y con poca factibilidad de observar con precisión eventuales actuaciones y resultados del "agente".

Es claro que el problema del riesgo moral genera importantes inconvenientes al "principal". Por ello, éste tiene que emprender acciones tendientes a aminorar el problema de agencia, a través de diversos mecanismos que, por cierto, son costes, los cuales se implementarán en la medida que la relación coste/beneficio se lo permita. Un mecanismo generalmente utilizado son las políticas de compensación a la dirección, vinculadas a los resultados, como por ejemplos un porcentaje de las ventas, gratificaciones en relación al monto de utilidad, o bien que el agente de la alta dirección pueda tener participación en la propiedad de la empresa mediante la adquisición de acciones, etc.
De acuerdo a Milgrom y Robert (1993), el riego moral, es una forma de oportunismo post-contractual que aparece porque algunas acciones que afectan a la eficiencia no son fácil y gratuitamente observables y así, la persona que las realiza puede elegir la persecución de su propio interés personal a expensas de los otros Sostienen además que en la relación de agencia, existe problemas de riesgo moral, debido a que el agente pueda utilizar maliciosamente las facultades que le han sido otorgadas por el principal o ante la existencia de contratos incompletos, para alcanzar objetivos personal en detrimento y a expensas del principal.

\subsection{Paralelo entre las contribuciones y críticas}

En general, son múltiples los aportes que esta teoría o enfoque, ha realizado, a la comprensión del comportamiento de los individuos dentro de las organizaciones, facilitando con ello la interpretación de una serie de fenómenos de la realidad empresarial; pero junto con ello, han emergido una gama de críticas, las cuales, si bien es cierto no tienen una amplia aceptación, de todos modos resulta útil conocerlas. Para una mayor comprensión de esta perspectiva dual, en el Cuadro 1 se muestra un parangón con ambas formas de ver esta teoría.

\section{Las universidades en Chile}

Como nuestro tema es el gobierno universitario, analizado desde la óptica de la teoría de agencia, es necesario establecer nexos entre estas variables; pero además es esencial, conocer aspectos relacionados con el sistema universitario chileno. 


\section{Teoría de agencia: contribuciones y críticas}

\begin{tabular}{|c|c|c|c|}
\hline Variables & Contribuciones & Variables & Críticas \\
\hline \multirow[t]{2}{*}{$\begin{array}{c}\text { Aporte a las } \\
\text { ciencias sociales }\end{array}$} & $\begin{array}{l}\text { Enfoque flexible, dado } \\
\text { que se puede aplicar en } \\
\text { las diversas áreas de la } \\
\text { administración de em- } \\
\text { presas. }\end{array}$ & & $\begin{array}{l}\text { Considera el comporta- } \\
\text { miento de los indivi- } \\
\text { duos como oportunis- } \\
\text { tas. }\end{array}$ \\
\hline & $\begin{array}{l}\text { Se han realizado gran- } \\
\text { des investigaciones en } \\
\text { el ámbito de las cien- } \\
\text { cias económicas y fi- } \\
\text { nancieras. }\end{array}$ & $\begin{array}{c}\text { Visión de las } \\
\text { personas }\end{array}$ & $\begin{array}{l}\text { Puede generar ego- } \\
\text { centrismo en las perso- } \\
\text { nas, dado que el mode- } \\
\text { lo no le da mucha im- } \\
\text { portancia a los aspec- } \\
\text { tos cooperativos. }\end{array}$ \\
\hline Metodología & $\begin{array}{l}\text { Ha desarrollado una } \\
\text { metodología original en } \\
\text { el campo de las organi- } \\
\text { zaciones. }\end{array}$ & & $\begin{array}{l}\text { Podría afectar la poten- } \\
\text { cialidad del trabajo en } \\
\text { equipo. }\end{array}$ \\
\hline \multirow[t]{2}{*}{$\begin{array}{c}\text { Aporte a la } \\
\text { administración } \\
\text { de personal }\end{array}$} & $\begin{array}{l}\text { Explica con nitidez las } \\
\text { relaciones de empleo y } \\
\text { los sistemas retributi- } \\
\text { vos. }\end{array}$ & & $\begin{array}{l}\text { Se centra principal- } \\
\text { mente en facetas eco- } \\
\text { nómicas de las perso- } \\
\text { nas }\end{array}$ \\
\hline & $\begin{array}{l}\text { Identifica y explica cla- } \\
\text { ramente las diversas } \\
\text { relaciones que se dan } \\
\text { entre los individuos al } \\
\text { interior de las organiza- } \\
\text { ciones. }\end{array}$ & Metodología & $\begin{array}{l}\text { Los estudios son de na- } \\
\text { turaleza estática, sin } \\
\text { capacidad de explicar } \\
\text { el fenómeno del cam- } \\
\text { bio en las organizacio- } \\
\text { nes. }\end{array}$ \\
\hline \multirow[t]{2}{*}{ Control } & $\begin{array}{l}\text { Ha definido innovado- } \\
\text { res mecanismos de ali- } \\
\text { neación de intereses }\end{array}$ & Capacitación & $\begin{array}{l}\text { No considera los proce- } \\
\text { sos de aprendizaje y de } \\
\text { acumulación de cono- } \\
\text { cimientos. }\end{array}$ \\
\hline & & Estructura & $\begin{array}{l}\text { Orientadas primordial- } \\
\text { mente al seguimiento y } \\
\text { control de los indivi- } \\
\text { duos. }\end{array}$ \\
\hline
\end{tabular}

Fuente: Diseño propio: sobre la base de lo argumentado por Arruñada 1990; Nilakant 1994, Pérez y Mozo, 2000.

Las universidades, al igual que cualquier tipo de organización, necesitan de un sistema de gobierno que posibilite la planificación, organización, dirección y control de su quehacer inmediato como de largo plazo. Se debe reconocer ade- más, que siempre se hará imprescindible el gobierno corporativo, cuando se esté en un contexto donde una persona, o un grupo de personas, asumen la tarea de tomar decisiones que tienen efecto en un número determinado de individuos que 
son obviamente diferentes a los personajes que deciden.

Es así como en las universidades, se asumen sistemas de gobierno, donde se conjugan autoridades unipersonales y cuerpos colegiados. En el caso de las primeras, la autoridad máxima está representada por el Rector quien asume la administración académica, económica y financiera, en conjunto con el denominado "Equipo de Rectoría", el cual lo componen habitualmente el Prorrector, el Vicerrector Académico y el Vicerrector de Administración y Finanzas. Concomitantemente existen autoridades pluripersonales, como por ejemplo: las Juntas Directivas o Consejos Superiores y los Consejos Universitarios o Consejos Académicos; como los más relevantes. En este orden de cosas, es donde es posible plantear que bajo el prisma de la teoría de agencia, en el campo de las universidades tradicionales, el principal lo constituye la sociedad la cual delega sus atribuciones en un cuerpo colegiado que puede ser la junta directiva, el directorio o el Consejo Superior ${ }^{7}$. Son éstos quienes encargan la gestión a un agente, que para este caso, está representado por el rector.

Situación similar ocurre con las universidades privadas, con la salvedad que su junta directiva esta compuesta por representantes de los dueños o accionistas. Esquemáticamente, lo expresado puede observarse en el Diagrama 1.

\section{- El contexto de las universidades}

Evidentemente los nuevos escenarios organizacionales, han complejizado abrumadoramente la educación superior en Chile, implicando ineluctablemente

\section{Diagrama 1 \\ Principal y Agente en empresas productivas y universidades}

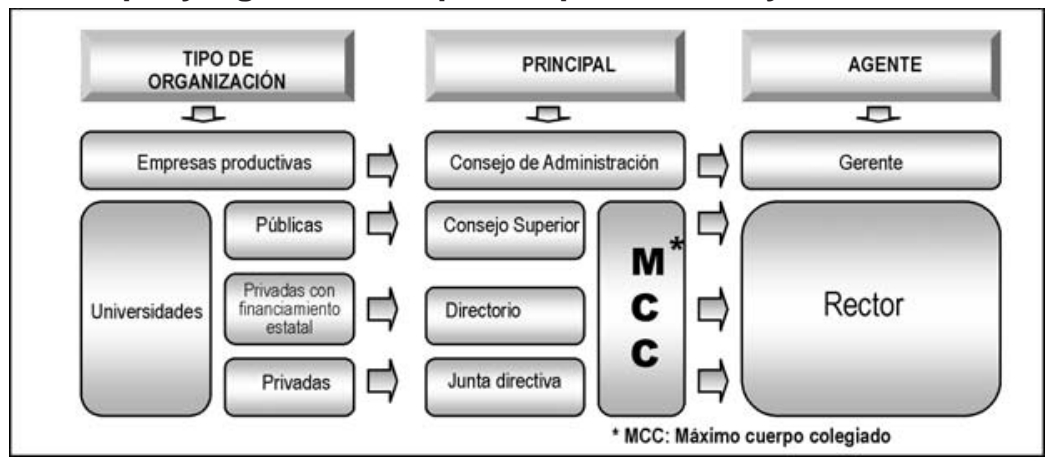

Fuente: Diseño propio basado en los estatutos de las universidades: Los Lagos, Austral de Chile y Autónoma del Sur.

7 Para el caso de las universidades en Chile, entenderemos por principal al máximo cuerpo colegiado (MCC). 
nuevos desafíos que deben ser asumidos. Estos contextos han determinado la necesidad de asumir el mejoramiento de la calidad de la educación terciaria en todos sus niveles y fomentar la igualdad de oportunidades, tanto en el acceso como en la permanencia en el sistema, sin homogeneizar a las instituciones y atendiendo a una demanda creciente (Armanet 2000).

Pareciera ser que estamos frente a un gran conflicto puesto que el actual sistema de educación superior no ha resuelto los problemas de equidad y ha generado muchas oportunidades especialmente para aquellos que cuentan con los recursos económicos. Pero el resto de la población, debe optar por un sistema público que debe hacer grandes esfuerzos para mantener su excelencia académica y continuar por la senda no solo de la docencia, sino también de la extensión y sobretodo la investigación, siendo esta última área, en la mayoría de los casos, inviable en términos económicos (por lo menos en el corto plazo), razón por la cual el sistema privado privilegia primordialmente la docencia.

Actualmente existen antecedentes que muestran nítidamente las profundas transformaciones estructurales que han perturbado en forma drástica el panorama de este relevante sector de la sociedad. También, a nivel general, es claro que estamos en un mundo que requiere ser observado con profundidad y detenimiento por las universidades, ya que se está dando paso a un nuevo tipo de organización social -del trabajo, de los intercambios, de la experiencia y las formas de poder- que se ha dado en llamar una sociedad global de la información, sus- tentada por una economía cuya base es la utilización del conocimiento (Brunner, 2003).

En un ámbito más local, afectado obviamente por lo general, se podría citar el acelerado incremento en la cobertura del sistema universitario, que particularmente en Chile ha implicado que en las últimas décadas se haya pasado desde un $2 \%$ a un $3 \%$ promedio, a una cifra que bordea el $15 \%$ del respectivo universo geográfico. Esto se ha traducido en un notable aumento del número de matriculados, tanto a nivel de pre-grado, como también en lo referente a los post-títulos y post-grados. Un detalle de lo afirmado, es posible observarlo en la Tabla 1.

Estos cambios producidos han posibilitado la emergencia de una serie de problemáticas en la totalidad del sistema, de la misma forma, ha permitido poner en la mesa de discusión la manera como se organizan las universidades, desde la perspectiva de su arquitectura organizacional, procesos involucrados y, por supuesto, la eficiencia y el rol que le compete en la sociedad chilena.

\section{Las universidades públicas y las universidades privadas}

Otro de los factores que configuran esta nueva realidad universitaria, viene representado por la coexistencia del sector público y privado. Este último ha mostrado un elevado dinamismo presentando con ello un alto nivel de heterogeneidad en sus esquemas de funcionamiento, estructura de gobierno corporativo y por supuesto de la calidad.

Toda esta plétora de cambios requiere repensar los actuales sistemas 


\section{Tabla 1}

Matrículas en las universidades chilenas (período 1983-2001)

\begin{tabular}{|c|c|c|c|c|c|c|c|}
\hline \multirow[t]{2}{*}{ Año } & \multicolumn{2}{|c|}{$\begin{array}{c}\text { № Matriculados } \\
\text { Pre-Grado }\end{array}$} & \multicolumn{2}{|c|}{$\begin{array}{c}\text { № Matriculados } \\
\text { Post-Título }\end{array}$} & \multicolumn{2}{|c|}{$\begin{array}{c}\text { № Matriculados } \\
\text { Post-Grado }\end{array}$} & \multirow[t]{2}{*}{$\begin{array}{r}\text { Total de } \\
\text { matrícula }\end{array}$} \\
\hline & $\begin{array}{l}\text { Us. Consejo } \\
\text { de Rectores }\end{array}$ & $\begin{array}{c}\text { Us. } \\
\text { Privadas }\end{array}$ & $\begin{array}{l}\text { Us. Consejo } \\
\text { de Rectores }\end{array}$ & $\begin{array}{c}\text { Us. } \\
\text { Privadas }\end{array}$ & $\begin{array}{l}\text { Us. Consejo } \\
\text { de Rectores }\end{array}$ & $\begin{array}{c}\text { Us. } \\
\text { Privadas }\end{array}$ & \\
\hline 1983 & 105.341 & 2.708 & 151 & 0 & 1.933 & 0 & 112.116 \\
\hline 1985 & 108.674 & 4.951 & 2.155 & 0 & 2.299 & 0 & 120.064 \\
\hline 1987 & 113.567 & 7.652 & 3.309 & 0 & 2.571 & 0 & 129.086 \\
\hline 1989 & 102.185 & 13.773 & 2.105 & 0 & 1.300 & 0 & 121.352 \\
\hline 1990 & 108.119 & 19.509 & 1.931 & 0 & 2.143 & 0 & 133.692 \\
\hline 1991 & 114.698 & 28.828 & 1.719 & 0 & 1.475 & 0 & 148.711 \\
\hline 1992 & 122.736 & 40.690 & 2.926 & 0 & 1.940 & 0 & 170.284 \\
\hline 1993 & 138.267 & 49.986 & 2.796 & 0 & 3.283 & 0 & 196.325 \\
\hline 1994 & 145.744 & 59.994 & 2.166 & 0 & 3.660 & 0 & 213.558 \\
\hline 1995 & 154.885 & 69.004 & 2.633 & 207 & 4.332 & 166 & 233.222 \\
\hline 1996 & 167.282 & 77.212 & 4.032 & 888 & 3.627 & 465 & 255.502 \\
\hline 1997 & 175.641 & 84.149 & 4.805 & 758 & 3.643 & 599 & 271.592 \\
\hline 1998 & 188.522 & 86.061 & 5.807 & 831 & 5.644 & 805 & 289.668 \\
\hline 1999 & 195.372 & 90.985 & 5.626 & 826 & 5.576 & 1.010 & 301.394 \\
\hline 2000 & 201.186 & 101.386 & 7.611 & 1.201 & 6.487 & 1.218 & 321.089 \\
\hline 2001 & 213.905 & 104.390 & 5.478 & 1.146 & 8.143 & 3.200 & 338.263 \\
\hline
\end{tabular}

Fuente: Diseño propio, basado en MINEDUC 2003.

que rigen la educación superior, más aún si consideramos que en el año 1980 el Decreto con Fuerza de Ley (DFL) $N^{\circ} 1$ que estableció como único mecanismo de control la supervisión que debía efectuar el Ministerio de Educación a los estatutos de las nuevas instituciones. La carencia de una normativa más estricta en el ámbito de la creación de nuevas universidades posibilitó la germinación profusa de instituciones de educación superior.

De esta forma, nos encontramos con el hecho de que así como hasta el año 1980 , sólo existían ocho universidades ${ }^{8}$ en Chile, a partir del año 1990 esta cifra

8 Estas ocho universidades eran las siguientes: Pontificia Universidad Católica de Chile, Universidad Austral de Chile, Universidad Católica de Valparaíso, Universidad Católica del Norte, Universidad de Chile, Universidad de Concepción, Universidad de Santiago de Chile (ex UTE) y Universidad Técnica Federico Santa María. 


\section{Gráfico 1}

Evolución de las universidades en Chile (período 1980-2001)

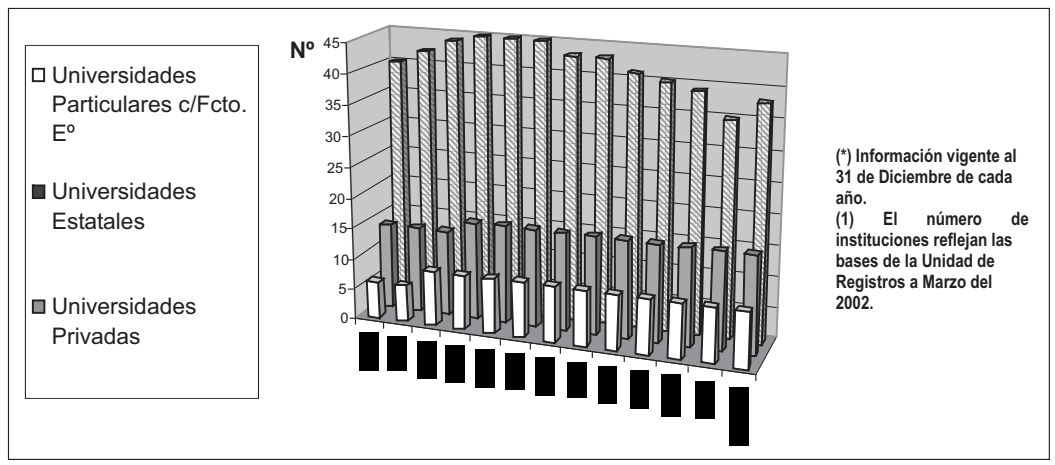

Fuente: Diseño propio basado en MINEDUC 2003.

aumentó a un total de sesenta, llegando a sesenta y tres el año $2002^{9}$. Estos datos pueden observarse en el Gráfico 1.

\subsection{La nueva estructura educacional chilena}

Complementario a lo expresado en el punto anterior, es relevante mencionar que previo al golpe de Estado del año 1973, en Chile las ocho universidades tradicionales eran las protagonistas de la educación post-media ${ }^{10}$, ya que ofrecían un basto abanico de opciones formativas, incursionando inclusive en ofertas de carreras de nivel técnico superior ${ }^{11}$.

Con el quiebre del sistema democrático y la llegada al poder del régimen militar, comenzaron a gestarse una serie de mutaciones que provocaron la aflora- ción de una basta gama de procesos, que reconfiguraron el contexto político, económico, social y los estilos de desarrollo de las universidades. Entre las decisiones que se tomaron, podrían citarse la supresión de las carreras técnicos-profesionales, se menguaron los aportes estatales directos y se generaron las condiciones para que las instituciones aplicaran políticas agresivas de cobros arancelarios, cuyos montos se acrecentaron en el tiempo.

También se podría anexionar el hecho de que a partir del año 1977, el gobierno militar inicia un cambio en la composición de sus colaboradores, debido a que se adicionan un número creciente de civiles, quienes asumen cargos ministeriales. Estos nuevos personeros fueron clave en la conformación de una nueva

9 Esta cifra disminuyo al año 2004, por el cierre de tres universidades privadas.

10 Se entiende por educación post-media, aquella que viene a posteriori de los ocho años de la denominada enseñanza básica y de los cuatro año de la llamada enseñanza media.

11 Estas carreras tenían por lo general una duración de cinco semestres. 
arquitectura política, la cual tenía alcances más globales en lo referente a las instituciones de educación superior.

De este modo se transitó hacia la denominada "Nueva Institucionalidad", proceso que culminó con la aprobación de una nueva Constitución Política en el año 1980. Ese mismo año, se estructuró una comisión interministerial, que tenía como finalidad primordial, abordar decididamente la modernización de la educación superior, teniendo como marco inspiratorio el pensamiento neoliberal y la doctrina de seguridad nacional.

En este contexto, se dictaron entre el mes de diciembre de 1980 y noviembre de 1981 una serie de normativas que se constituyeron en verdaderos corpus legales de la época, con el claro propósito de transformar el sistema de educación superior, caracterizados por una posición nuclear de las universidades, por otro que fuese más vasto y diversificado, es decir, con mayores alternativas para los poten- ciales estudiantes. Fue así como se diseñó una división vertical tripartita de instituciones, donde cada grupo tenía sus propios objetivos y orientaciones ${ }^{12}$. El Diagrama 2 esquematiza este nuevo escenario educacional.

En cuanto, a las estructuras que se definieron en esa época, es factible citar los mecanismos institucionales de regulación directa, como es el caso de las formas ideadas para financiar con fondos públicos las acciones que se deberían realizar en este sector, como a su vez, generar las condiciones privatizadoras; de forma tal, que se fomente la competencia en esta "industria" emergente. De esta forma se produjo una apertura del sistema, que trajo consigo la gestación de nuevas instituciones. Esta situación a trasladado la responsabilidad en el crecimiento desde el sector estatal al privado y de paso, a cambiado la óptica de la problemática cuantitativa a la cualitativa.

\section{Diagrama 2}

\section{La pirámide educacional en Chile}

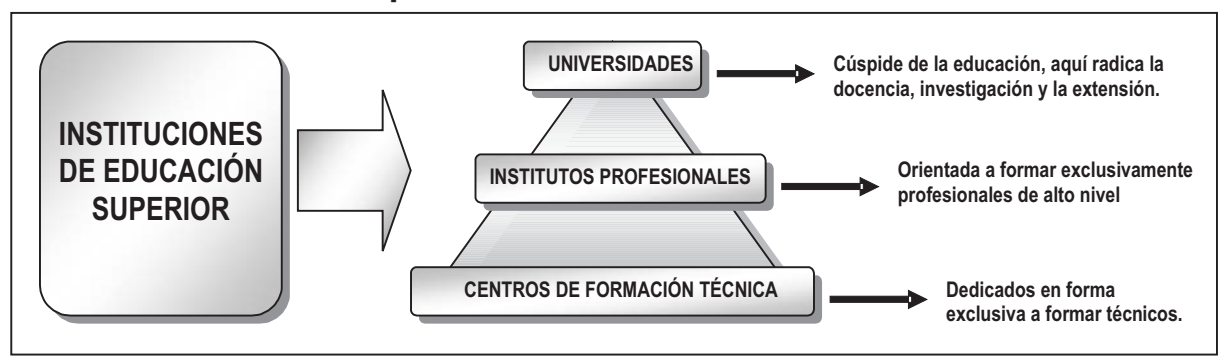

Fuente: Diseño propio, basado en MINEDUC 2003.

12 Para efectos de este trabajo, no se consideran en los análisis los Establecimientos de Educación Superior de las Fuerzas Armadas y de Orden, los cuales forman un cuarto componente del sistema. 
Una mención especial merecen las universidades regionales de carácter público, las cuales han debido realizar magnos esfuerzos para sobrevivir y lograr su afianzamiento. Lo anterior debido a las grandes limitaciones presupuestarias que han enfrentado, junto a modificaciones permanentes en la asignación de los recursos fiscales.

Es así como el mapa universitario ha quedado conformado por instituciones que albergan en su seno una amplia variedad de disciplinas, con un crecimiento uniforme y racional de éstas. Sin embargo, también es factible detectar algunas instituciones con mínima infraestructura y circunscritas a un par de áreas disciplinarias, las que generalmente están radicadas de manera principal en la docencia ${ }^{13}$.

En el hogaño, estamos en presencia de una multidiversidad de instituciones de educación superior, con diferentes niveles de cobertura, excelencia, posicionamiento, crecimiento y desarrollo. El sector se ha tornado hipercompetitivo, con universidades que han extendido sus tentáculos de manera transversal a las diferentes regiones.

Para el estudio de carácter exploratorio, se seleccionaron tres universidades: De Los Lagos, Austral de Chile y Autónoma del Sur, por los siguiente motivos: son universidades regionales ${ }^{14}$ de similar tamaño y, cada una representa a los tres tipos de universidades que existen en Chile, desde el punto de vista jurídico ${ }^{15}$.

En el Cuadro 2 presenta un resumen con las principales características de los tres casos seleccionados:

\section{Análisis exploratorio y discusión de resultados parciales}

Se exponen a continuación los resultados de las variables estudiadas a partir de información proveniente de encuesta a los rectores y miembros de los MCC. La idea es presentar y describir una serie de características que se dan en la relación entre estos dos entes.

\subsection{Asimetrías de información}

Uno de los objetivos planteados, decía relación con la determinación del nivel de existencia de asimetrías de informativas entre los miembros de los MCC y los rectores de las universidades analizadas.

Para lograr este objetivo, se confeccionaron una serie de preguntas (1. Características de la universidad), relacionadas con diversos tópicos de orden específico, éstos se contrastaron con las respuestas dadas por los rectores y miembros de los MCC. Los resultados se entregan en la Tabla 2. La idea era determinar el nivel de información que tenían

13 La mayoría de estas instituciones heredaron la calidad y los recursos restrictivos de sus matrices nacionales, esto es: la Universidad de Chile y Universidad Técnica del Estado.

14 La Universidad De Los Lagos y la Universidad Austral de Chile, se encuentran ubicadas en la X Región, y la Universidad Autónoma del Sur, ubicada en la IX Región.

15 Los tres tipos de universidades existentes son: Corporaciones de derecho público, Corporaciones de derecho privado con financiamiento estatal y Corporaciones de derecho privado. 


\section{Cuadro 2}

\section{Antecedentes generales de las universidades seleccionadas como}

\begin{tabular}{|c|c|c|c|c|c|}
\hline Universidad & Nacimiento & Naturaleza & $\begin{array}{l}\text { Misión (de acuerdo a } \\
\text { Estutos Orgánicos) }\end{array}$ & $\begin{array}{l}\text { № Alumnos } \\
\text { Pre-grado }\end{array}$ & $\begin{array}{c}\text { Ubicación } \\
\text { Casa } \\
\text { Central }\end{array}$ \\
\hline $\begin{array}{l}\text { De Los } \\
\text { Lagos }\end{array}$ & $\begin{array}{c}30 \text { de } \\
\text { agosto de } \\
1993\end{array}$ & $\begin{array}{l}\text { Corporación } \\
\text { de derecho } \\
\text { público }\end{array}$ & $\begin{array}{l}\text { Se orienta a "ocuparse, en } \\
\text { un nivel avanzado, de la } \\
\text { creación, cultivo y transmi- } \\
\text { sión de conocimientos, por } \\
\text { medio de la investigación } \\
\text { básica y aplicada, la do- } \\
\text { cencia, y la extensión; de } \\
\text { la formación académica, } \\
\text { científica, profesional y } \\
\text { técnica y, en general del } \\
\text { cultivo general de las ar- } \\
\text { tes, las letras y las cien- } \\
\text { cias" (Art } 2^{\circ} \text { ley 19.238). }\end{array}$ & 3.800 & Osorno \\
\hline $\begin{array}{l}\text { Austral } \\
\text { de Chile }\end{array}$ & $\begin{array}{c}16 \text { de } \\
\text { febrero de } \\
1954\end{array}$ & $\begin{array}{l}\text { Corporación } \\
\text { de derecho } \\
\text { privado, con } \\
\text { financiamien } \\
\text { to estatal }\end{array}$ & $\begin{array}{l}\text { "Contribuir al desarrollo } \\
\text { espiritual y material de la } \\
\text { nación mediante los recur- } \\
\text { sos del saber científico, } \\
\text { tecnológicos, de las artes } \\
\text { y de las letras en sus más } \\
\text { altas manifestaciones" }\end{array}$ & 8.900 & Valdivia \\
\hline $\begin{array}{l}\text { Autónoma } \\
\text { del Sur }\end{array}$ & $\begin{array}{l}1989 \text { y en- } \\
\text { tra en fun- } \\
\text { cionamien- } \\
\text { to en marzo } \\
\text { de } 1990\end{array}$ & $\begin{array}{c}\text { Corporación } \\
\text { de derecho } \\
\text { privado. }\end{array}$ & $\begin{array}{l}\text { Formar profesionales califi- } \\
\text { cados y contribuir al desa- } \\
\text { rrollo nacional. Ha adopta- } \\
\text { do como lema "DUC IN AL- } \\
\text { TUM", frase latina en senti- } \\
\text { do estricto significa "condu- } \\
\text { cir hacia las alturas", pero } \\
\text { en una traducción más li- } \\
\text { bre viene a formular a la co- } \\
\text { munidad universitaria una } \\
\text { invitación a la superación } \\
\text { permanente. }\end{array}$ & 6.000 & Temuco \\
\hline
\end{tabular}

Fuente: Diseño propio, basado en Estatutos Orgánicos y en portal web de cada universidad. 


\section{Tabla 2}

Comparación del nivel de información acerca de la Universidad por rectores y miembros de los MCC (Valores expresados en porcentajes)

\begin{tabular}{|c|c|c|c|c|c|c|c|c|}
\hline \multirow{3}{*}{ Preguntas } & \multicolumn{8}{|c|}{ Respuestas } \\
\hline & \multicolumn{4}{|c|}{ Rectores } & \multicolumn{4}{|c|}{ MCC } \\
\hline & $\begin{array}{c}\text { № } \\
\text { exacto }\end{array}$ & $\begin{array}{c}\text { № } \\
\text { aproximado }\end{array}$ & No sabe & N/R & $\begin{array}{c}\text { № } \\
\text { exacto }\end{array}$ & $\begin{array}{c}\text { № } \\
\text { aproximado }\end{array}$ & No sabe & N/R \\
\hline $\begin{array}{l}\text { № } \\
\text { Funcionarios }\end{array}$ & 0,0 & 100,0 & 0,0 & 0,0 & 0,0 & 29,4 & 64,7 & 5,9 \\
\hline № Acad. J/C & 0,0 & 100,0 & 0,0 & 0,0 & 0,0 & 23,5 & 70,6 & 5,9 \\
\hline $\begin{array}{l}\text { № Acad. } \\
\text { 1/2/J }\end{array}$ & 0,0 & 100,0 & 0,0 & 0,0 & 0,0 & 11,8 & 82,4 & 5,9 \\
\hline № & & & & & & & & \\
\hline $\begin{array}{l}\text { Alumn.Tot. } \\
\text { PreG }{ }^{\circ}\end{array}$ & 66,7 & 33,3 & 0,0 & 0,0 & 0,0 & 82,4 & 11,8 & 5,9 \\
\hline $\begin{array}{l}\text { № Proy. en } \\
\text { Ejec. }\end{array}$ & 0,0 & 100,0 & 0,0 & 0,0 & 0,0 & 17,5 & 76,5 & 5,9 \\
\hline $\begin{array}{l}\text { № Carr. } \\
\text { PreGo }\end{array}$ & 33,3 & 66,7 & 0,0 & 0,0 & 5,9 & 41,2 & 47,1 & 5,9 \\
\hline $\begin{array}{l}\text { Total } \mathrm{M}^{2} \\
\text { Cont. }\end{array}$ & 0,0 & 100,0 & 0,0 & 0,0 & 0,0 & 5,9 & 88,2 & 5,9 \\
\hline $\begin{array}{l}\text { Total Ing. } \\
\text { por AFD }\end{array}$ & 33,3 & 66,7 & 0,0 & 0,0 & 0,0 & 11,8 & 82,4 & 5,9 \\
\hline $\begin{array}{l}\text { Total Ing. } \\
\text { por AFI }\end{array}$ & 0,0 & 100,0 & 0,0 & 0,0 & 0,0 & 118,8 & 82,4 & 5,9 \\
\hline Ing. propios & 0,0 & 66,7 & 0,0 & 33,3 & 0,0 & 17,6 & 76,5 & 5,9 \\
\hline $\begin{array}{l}\text { Renta Prom. } \\
\text { Alnado. }\end{array}$ & 0,0 & 66,7 & 33,3 & 0,0 & 0,0 & 58,8 & 35,3 & 5,9 \\
\hline
\end{tabular}

N/R: Significa no responde.

Fuente: Encuesta realizada por el autor a los rectores y miembros de los MCC.

sobre estos temas, tanto el principal como el agente, es por ello que se les dio la posibilidad de responder si sabían con exactitud los que se les inquiría si tenían una aproximación de respuesta o si no tenían ninguna idea respecto de lo que se le indagaba.

En la tabla presentada, se denota con claridad el nivel de desconocimiento que tienen los miembros de los MCC, respecto de cuestiones propias de su universidad, situación que no ocurre con los rectores. Nótese que en el $55 \%$ del total de las preguntas formuladas en este item, los tres rectores sabían el "número aproximado" de lo que se le preguntaba. Es más, algunos rectores entregaron en tres, de las once preguntas enunciadas, 
el "dato exacto" de lo que se les consultaba.

En el caso de los miembros de los MCC, la situación es completamente diferente, pues, en ocho de las once preguntas expresadas, el $77,9 \%$ promedio, responde que "no sabe" lo que se le consulta. Sólo en una pregunta, el porcentaje que responde "№ aproximado", sobrepasa levemente el $82 \%$.

El conocimiento de los rectores sobre la universidad es evidentemente mejor que el de los miembros de los MCC, poniéndose de manifiesto, cuando se les pregunta "si creían que existía asimetrías de información entre ellos". Fue así como los rectores concordaron que si existe asimetrías de información con los "principales". Estos últimos, en un 70,6\% manifestaron la misma opinión, respecto de los rectores. Estas asimetrías se producen a "nivel medio", según los rectores, y a "nivel medio y alto", en la perspectiva de los miembros de los MCC.

Los resultados arrojados, confirman el hecho, que lo que ocurre en el gobierno universitario -en lo que a asimetrías de información entre principal y agente se refiere- no es muy diferente a lo que acontece en el gobierno de las empresas, es decir, se puede percibir de manera clara, que lamentablemente los miembros de los MCC no están informados de lo que acontece en sus organizaciones, y al tener poca información, difícilmente pueden ayudar a que se tomen mejores decisiones; por lo mismo, muchos han planteado que estos organismos ocupan un rol de carácter consultivo, más que de control, de la gestión que realizan los rectores. Por lo tanto, se cumple y se confirma que efectivamente la información que maneja los "directivos" de las universidades es cuantitativa y cualitativamente superior a la que manejan los "principales".

\subsection{Alineación de intereses}

Este propósito estaba orientado a analizar el nivel de divergencia de intereses que pudiese existir entre los rectores y los miembros de los máximos cuerpos colegiados de las universidades estudiadas.

Para ello se le entregó a cada entrevistado un listado de 13 objetivos que

\section{Tabla 3 \\ Recodificaciones de objetivos prioritarios, evaluados por encuestados}

\begin{tabular}{lc}
\hline Concepto & Evaluaciones \\
\hline Bajo interés & De 1 a 5 \\
Medio interés & De 6 a 9 \\
Alto interés & De 10 a 13 \\
\hline
\end{tabular}

Fuente: Encuesta realizada por el autor.

pudiesen ser de su interés. En seguida, se les solicitó que los jerarquizaran de 1 a 13, según sea la importancia, de menos relevante a más importante. Estos valores están recodificados en la Tabla 3.

Como se observa en los Gráficos 2 y 3 , la alineación de intereses entre el rector y los miembros de los MCC, se da prácticamente en dos objetivos, como son los de "formar profesionales integrales" " "contribuir a la sociedad", en ambos casos, más del $60 \%$ de los rectores y miembros de los MCC, le dan una calificación de "alto interés" para su gestión. Frente a la opción "medio interés", no existen coincidencias entre los rectores y 


\section{Gráfico 2}

\section{Prioridades en los objetivos de rectores en tres universidades chilenas}
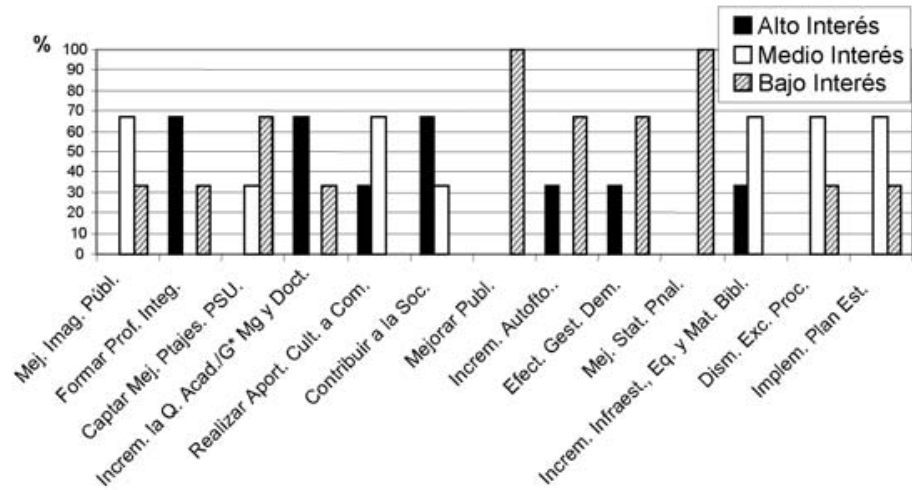

Fuente: Encuesta realizada por el autor.

\section{Gráfico 3}

\section{Prioridades en los objetivos de los miembros de los MCC en tres universidades chilenas}
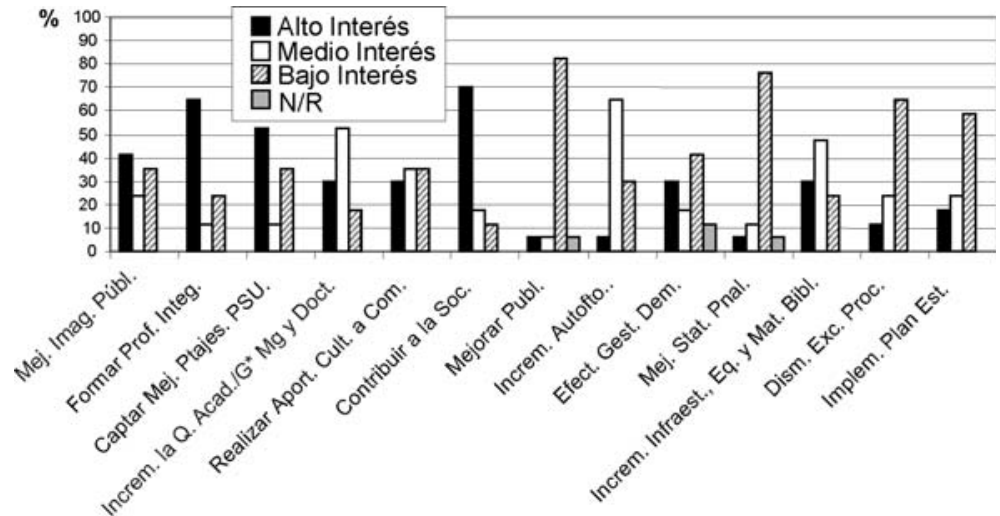

Fuente: Encuesta realizada por el autor.

los miembros de los MCC. Esto si se da en dos objetivos que fueron evaluados como de "bajo interés"; al respecto, más del $70 \%$ de los encuestados (principal y agente), coinciden en darle esta valoración, a los objetivos "mejorar publicidad" y "mejorar estatus personal".

Los resultados analizados ponen de manifiesto las divergencia de intere- ses entre rectores y miembros de los MCC; sin embargo, éstos no son coincidentes con la percepción que tienen los encuestados respecto de esta situación, dado que cuando se les pregunta si "han percibido divergencia entre ellos y su contraparte (rector o MCC, según corresponda), que hayan afectado la gestión del agente", el total de los rectores sostiene 
que "pocas veces". Para el caso de los miembros de los MCC, este porcentaje llega a un $50 \%$. Un porcentaje no menor de los miembros de los MCC (20\%) sostienen que "nunca" han percibido divergencia de intereses.

Luego se solicitó a los encuestados que "justifiquen las respuestas dadas previamente", y ocurre que dos de los tres rectores, sostienen que la divergencia de intereses obedece a que existe mucha "demora en la tramitación de proyectos esenciales", es decir, los miembros de los MCC, tienden a burocratizar la tramitación de proyectos que según la perspectiva de los rectores, son fundamentales para el progreso de la universidad. El otro rector se justifica, al plantear que percibe diferencias en "la visión y en las prioridades de asignación de recursos".

En los miembros de los MCC, las opiniones están bastante divididas, dado que sólo el $30 \%$ coincide al sostener que la divergencia de intereses obedece a "aspectos relacionados con la gestión". Es interesante, en todo caso, que más del $20 \%$ (que debe corresponder al porcentaje que sostiene que "pocas veces" o "nunca" hay divergencias de intereses) justifica su respuesta señalando que esta realidad obedece a que existe "buena comunicación", y cerca del $20 \%$ sostiene que lo que ha ayudado ha sido el "uso transparente de la información".

Respecto del nivel de coincidencia en las decisiones que se tomaban en ambas partes, los tres rectores unánimemente expresaron que "casi siempre" concordaban. Algo parecido ocurrió con los miembros de los MCC, donde prácticamente el $65 \%$ se manifestó a favor de esta opción. Pero, cuando se les solicita que justifiquen lo expresado previamente, a través de una pregunta abierta, se produce una diversificación de respuestas y sólo un rector concuerda con más del $40 \%$ de los miembros de los MCC, al apuntar que la coincidencia en las decisiones obedecía a que ambos entes están "orientados al mejoramiento universitario".

Como ha quedado de manifiesto, existe nítidamente divergencia de intereses entre principal y agente, de los casos estudiados. Esto se refuerza, si consideramos que en los ítems donde se percibió cierta coincidencia de intereses, son en general cuestiones frente a las cuales, cualquier persona, esté o no esté relacionada con el tema universitario puede compartir, dado que se trata de orientaciones donde en la sociedad en general existe cierto consenso.

De este modo, la idea de "analizar las posibles divergencias entre los intereses de los principales de las universidades chilenas y sus directivos superiores", queda materializada, dado que como se ha podido observar en los datos recopilados, éstas discordancia de intereses, si existen entre "agente" y "principal" de los casos seleccionados, y colateralmente, viene a apoyar la existencia de "asimetrías informativas", pues los encuestados están convencidos que en general los intereses están "alineados", cosa que a la luz de la información acopiada no es real. Esto, sin duda, puede generar descoordinaciones en los planteamientos y acciones directivas y afectar la eficiencia en la gestión, dado que el logro de los grandes objetivos de una organización, dependen del nivel de consenso en metas es- 
pecíficas, y para ello, se debe comenzar por tener intereses relativamente alineados.

\subsection{Eficiencia percibida}

Determinar la percepción que existe respecto de los niveles de eficiencia, no deja de ser un objetivo clave en el potencial mejoramiento de la gestión, dado que si no existe este auto análisis, difícilmente se pueden emprender acciones que corrijan las vulnerabilidades existentes, corriéndose el riesgo de mantenerse bajo prácticas inapropiadas, desde el punto de vista de la gestión.

En este sentido, la percepción con respecto a la forma como los encuestados evalúan la gestión del agente, en términos de eficiencia es muy relevante, y fue así como se encontró, que respecto de la constatación de este objetivo, existe un alto grado de coincidencia en los encuestados, dado que la mayoría considera, en términos generales, que la gestión de los rectores es "buena" (los tres rectores tienen esta opinión y en el caso de los miembros del MCC, el porcentaje llega prácticamente al $60 \%$ ).

En este mismo orden de cosas, y con la finalidad de identificar algunos factores que han determinado el éxito en la gestión de los rectores, se les pide a los encuestados que valoren en términos porcentuales (de $0 \%$ a $100 \%$ ), cuáles de los siguientes componentes han influido positivamente en la gestión. a) Volumen de los factores de producción (recursos económicos y financieros), b) Características profesionales (Ej. formación profesional, experiencia, capacidad de liderazgo, capacidad para trabajar en equipo), c) Esfuerzo personal, d) Elementos externos (Ej. nivel de ingreso de la población, imagen pública, pirámide demográfica). Los resultados obtenidos, se presentan en el Gráfico 4.

Como es factible observar en el Gráfico 4, según la percepción de los encuestados, los resultados obtenidos bajo

\section{Gráfico 4 \\ Factores determinantes de la eficiencia del rector en tres universidades Chilenas}

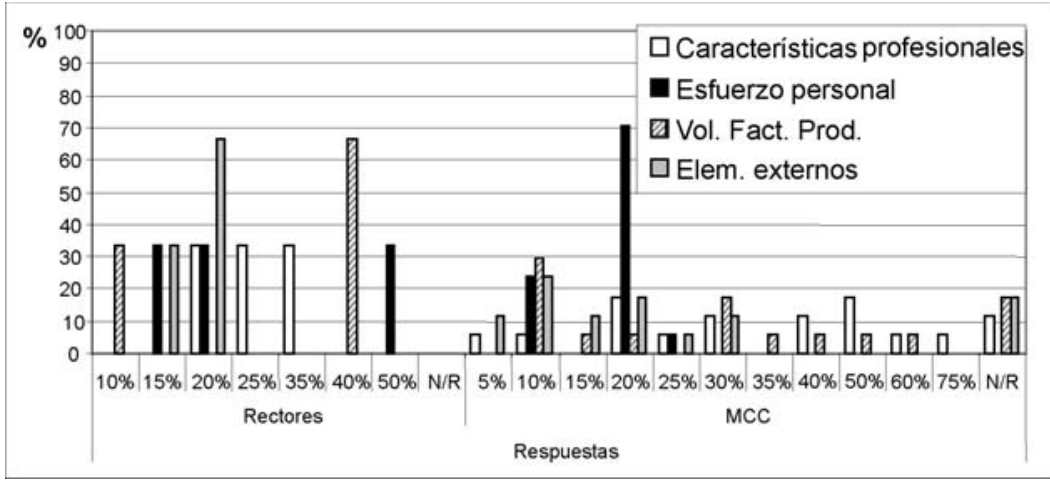

Fuente: Encuesta realizada por el autor. 
la gestión de los directivos, no dependen de un solo factor, sino que son producto de un "mix" de "factores críticos de éxito" (FCE). Es así como en el caso de los rectores, uno de ellos se inclinó por indicar que el éxito en su gestión, se debía en un $50 \%$ a su "esfuerzo personal", sin embargo, los otros dos rectores le dan a esta factor, una ponderación más bien baja (15\% y $20 \%$, respectivamente).

En cuanto a las "características profesionales", los agentes le conceden como FCE entre el $20 \%$ y el $35 \%$. En todo caso, el porcentaje que le dan de importancia a los otros dos factores analizados, es relativamente bajo, dado que cuando se trata de ponderar el efecto de los "elementos externos", el porcentaje que le otorgan los agentes, como FCE, no supera el $20 \%$. Respecto del efecto que tiene el "volumen de los factores de producción", las respuestas se dispersan, pues dos de los tres rectores le atribuyen un $40 \%$ como FCE, y el otro agente, sólo el 10\%.

$\mathrm{Si}$ las respuestas de los agentes son variadas, en el caso de los miembros de los MCC, el asunto es aún mayor. De los datos recolectados, es posible resaltar el hecho que casi un $43 \%$ de los "principales", les asigna a las "características profesionales" como FCE, entre el $40 \%$ y el $75 \%$. Igualmente, la evaluación que se hace del "esfuerzo personal"; un porcentaje significativo $(70,6 \%)$, considera que este ha influido en un $20 \%$ en el éxito de la gestión del agente.

Se evaluó el efecto que ha tenido el "volumen de los factores de producción" y los "elementos externos" como FCE en la gestión del agente. Al respecto los miembros de los MCC, le dan al segundo factor, una valoración más bien baja, de hecho, casi el $53 \%$, sólo le asigna entre un $10 \%$ y un $20 \%$ de relevancia, situación que no difiere mucho de lo que perciben del componente "volumen de los factores de producción" (58,8\% de los principales, le otorgan entre un $10 \%$ y un $30 \%$ como FCE).

De los resultados ya comentados, es posible desprender que al parecer los rectores, han realizado un buen trabajo de imagen, para mostrarse ante los principales como entes altamente comprometidos o con competencias profesionales suficientes para cumplir las responsabilidades que se les han asignado. De este modo, pensamos que se ha logrado el objetivo de "evaluar la percepción de los participantes, respecto del nivel de eficiencia del gobierno universitario". En este orden de cosas, es útil preguntarse si la impresión positiva que se tiene en términos generales de la gestión del agente, obedece a una labor sistemática de monitoreo de parte del principal, o sólo es producto de una visión sesgada obtenida de los flujos de información emanados desde los directivos. Lo que si está meridianamente claro, es que se ha mantenido una línea, respecto de las divergencias en las apreciaciones que tienen de los fenómenos organizacionales, los "agentes" y los "principales" de los casos en estudio.

\subsection{Mecanismos alineadores}

En el ámbito laboral, las personas tratan de maximizar la relación entre trabajo y ocio, dado que cuando se trabaja, los individuos lo hacen a costa del ocio. Mientras más se trabaja, menos tiempo se tiene para el ocio, lo cual implica que 
hay un coste de oportunidad que tiene que ser compensado de alguna forma, de lo contrario las personas intentarán escaquearse del trabajo.

En el contexto universitario esta realidad no es ajena, es por ello que se deben identificar "mecanismos alineadores de intereses" basados no sólo en compensaciones económicas, sino buscando el involucramiento (motivación intrínseca primordialmente), pues, como ya ha quedado de manifiesto, los agentes funcionan con un alto grado de autonomía y bajo estos esquemas, los problemas de "riesgo moral", se convierten en amenazas permanentes. De ahí la importancia de identificar aquellos tipos de incentivos, que más motivan a los agentes de las universidades. En este caso, la idea es identificar y presentar descriptivamente, el nivel de concordancia que existe entre principal y agente, respecto de los mecanismos alineadores y remarcar aquellos que son de un mayor interés para los directivos.

Cuando se analizan las respuestas obtenidas de los entrevistados, se perciben claramente "asimetrías de información" o "divergencia de intereses". Por ejemplo, más del $47 \%$ de los miembros de los MCC, estiman que la posibilidad de "ampliar relaciones" (contactos), significan para los rectores un incentivo "muy importante" y un porcentaje similar estimaba que era "importante". Al sumar ambos porcentajes, la cifra sobrepasa el $80 \%$. esto difiere con la percepción de los agentes, dado que sólo uno de ellos la consideró "muy importante", para otro era "indiferente" y el tercero simplemente no respondió.
Similar situación ocurrió con el tema de la "financiación de viajes", donde uno de los agentes respondió que esto era "importante", para el otro era "indiferente" y el tercero "no responde". En cambio, para los principales, casi el $53 \%$ sostiene que éste debiera ser un factor "importante", como mecanismo de incentivo en los rectores. En otros factores como el "estatus" y la "invitación a seminarios", se repite la tónica, con porcentajes similares a los entregados previamente.

En todo caso, también existen ciertas coincidencias, como ocurre en los factores "desarrollo profesional y autorrealización", donde dos de los tres rectores encuestados, le dan la categoría de "importante" y "muy importante" y en el caso de los miembros de los MCC, le atribuyen un $47 \%$, tanto a la opción "muy importante", como a la de "importante".

Algo similar ocurre con las preguntas que tienen que ver con la "ampliación de responsabilidad", donde los agentes se inclinaron en un $66,7 \%$, y los miembros de los MCC casi en un 53\%, por la valoración "importante". En todo caso, un mayor nivel de detalle, puede observarse en la Tabla 4, la cual muestra en la primera columna (de izquierda a derecha), una serie de "incentivos", los cuales debían ser evaluados por los encuestados en una escala de 1 a 5 , según el significado que aparece en la segunda fila (de arriba hacia abajo). Los resultados, en términos porcentuales, tanto de "agente" como de "principal", se muestran a partir de la cuarta fila.

Pero como ya ha quedado de manifiesto, la motivación también tiene un lado "extrínseco", es por ello que se le pregun- 
ta a los directivos, respecto del "nivel de conformidad" con su remuneración. Por su parte, a los miembros de los MCC, se les consulta su idea o percepción en cuanto al nivel de conformidad que tienen los agentes de la remuneración que se les paga.

Frente a tres opciones de respuesta ("alto", "medio" y "bajo"), dos de los tres rectores se inclinaron por manifestar un nivel "medio" de conformidad con la remuneración que recibían, en cambio, de la percepción de los miembros de los MCC, casi el $50 \%$ estimaba que los rectores debieran tener un "alto" nivel de conformidad con lo que reciben de paga.

Para poder acceder a un mayor nivel de información respecto de estas respuestas, se procedió a preguntarle a los entrevistados acerca del nivel de incremento que debieran tener las. Sólo un rector estimó que debieran aumentar en un $50 \%$, el segundo respondió que no se debieran aumentar y el tercero optó por no responder. En el caso de los miembros de los MCC, casi el $80 \%$ prefirió no dar una respuesta a esta pregunta.

Podemos por lo tanto señalar, que la motivación de los directivos, es factible lograrla por medio de un buen manejo de un "mix retributivo", dado que este conjunto posibilita la alineación de intereses ente "principal" y "agente". La duda que surge, a raíz de los resultados presentados, dice relación con el nivel de gravitación que tienen los miembros de los MCC, en la confección de los "mecanismos alineadores de intereses", pues, si el nivel de ingerencia es relativamente menor, cómo podrán a posteriori controlar o exigir determinados resultados. A si mis- mo, si determinados mecanismos son percibidos como relevantes para los "agentes", por parte de los "principales", y la práctica demuestra que esto no es real, cómo podrán los miembros de los MCC, propiciar y aprobar sistemas de incentivos que realmente motiven a los rectores. Las preguntas quedan lanzadas.

En todo caso, el propósito de "evaluar la percepción de los participantes, respecto de los principales mecanismos alineadores de intereses existentes en las universidades chilenas", queda claramente superado, dado que no sólo se ha obtenido una evaluación de lo que ocurre con los sistemas de incentivos, tanto intrínsecos como extrínsecos", si no que además, ha posibilitado la germinación de nuevas inquietudes.

\subsection{Mecanismos de control}

\section{Se estudiaran a continuación dos componentes del control, los cua- les se describen en:}

\section{- Control interno}

En el análisis, es factible percibir el bajo nivel de involucramiento de lo miembros de los MCC, dado que en general no existe una preocupación por explicitar el sistema de control al cual debiera estar sometido el agente. Es así como más del $66 \%$ de los rectores y los miembros de los MCC, coinciden en indicar que en los contratos iniciales "no se hace referencia al sistema de control", de allí que se entienda que ambos entes coinciden que el control interno más habitual al que se somete el agente, es el "control por resulta- 


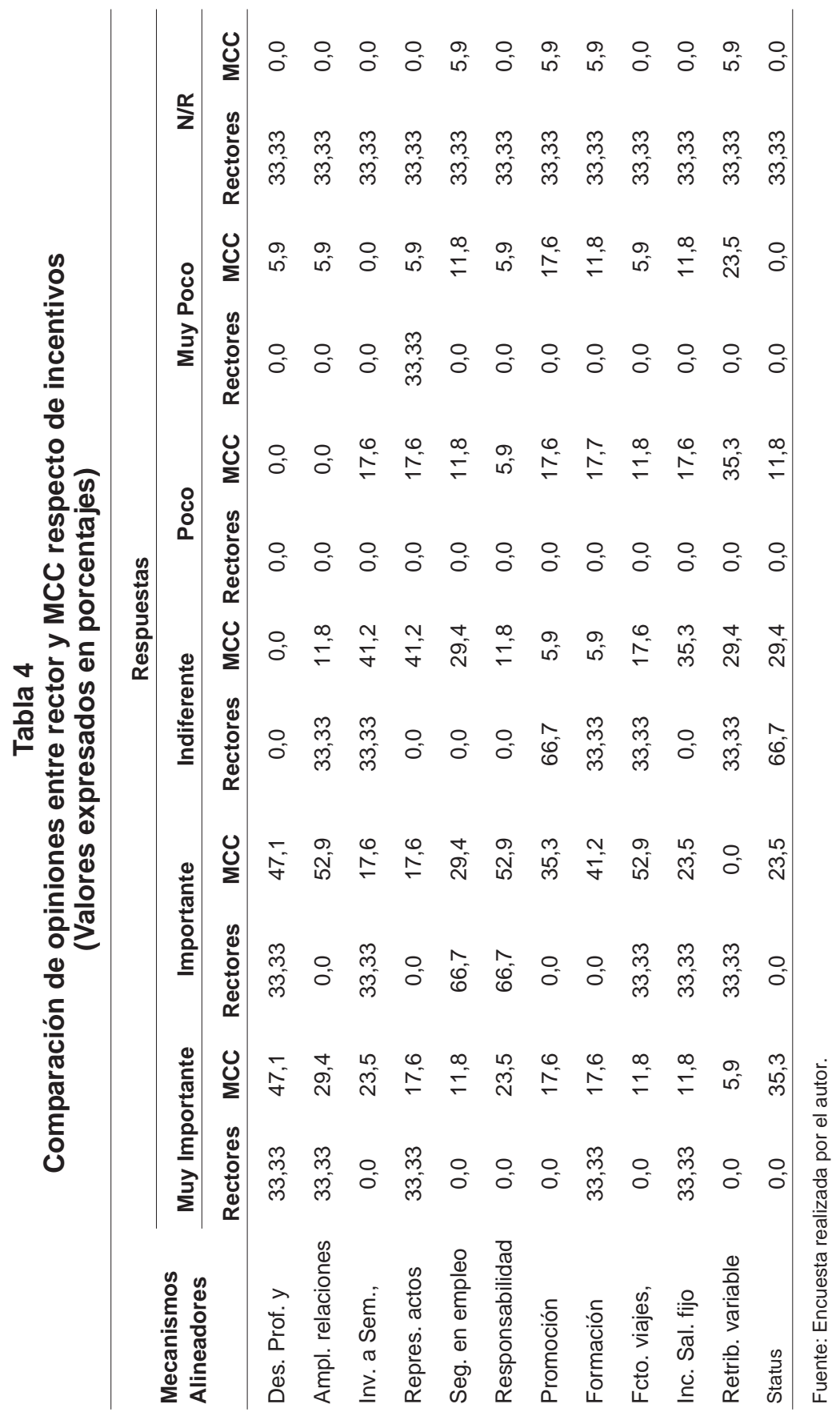


dos" (más del $58 \%$ de los encuestados); es más, existe un porcentaje no despreciable del principal $(23,5 \%)$, que considera que en general a los rectores no se le "somete a ningún tipo de control". Probablemente esta es la realidad más aplicable al sistema privado, que en general eligen a su "agente", sobre la base del nivel de participación económica que tengan en la universidad, los miembros del directorio o junta directiva. En el caso de las universidades públicas y las corporaciones de derecho privado con aportes estatales, los rectores duran cuatro años en sus cargos, pudiendo ser reelegidos, si cuentan con el apoyo de la mayoría de los docentes, que en este proceso eleccionario, se convierten en "principal" y votarán a favor o en contra de ese "agente", dependiendo de la percepción que tengan de la gestión que haya realizado el rector en ese periodo de cuatro años. Si la percepción es negativa, optarán por otra persona para reemplazarle.

Si embargo, a pesar de la nula existencia de una explicación, de parte del "principal", respecto del sistema de control interno al que se le iba a someter al rector, de todos modos, más del $58 \%$ de los encuestados consideran el sistema de control interno como "bueno" y sólo el $33,3 \%$ de los agentes y el $5,9 \%$ de los principales la califican de "malo".Como se observa, las respuestas tienden a ser contradictorias, pues por un lado se reconoce la inexistencia de un sistema de control interno apropiado y por otro lado se le califica como "adecuado".

De modo complementario se les pidió a los encuestados que justificaran la evaluación que hacían del sistema de control interno, dado que era necesario poder aclarar las eventuales contradicciones que fueran surgiendo. Como se trataba de una pregunta con "respuestas abiertas", se obtuvo una variedad de opiniones, donde es factible rescatar el hecho que un buen porcentaje $(33,3 \%$ de los rectores y $23,5 \%$ de los miembros de los MCC) planteara que el control podría ser evaluado como "bueno", pues, en general "nunca han existido problemas con el sistema de control externo".

Esta situación, de alguna forma viene a respaldar el planteamiento que ya se ha venido formulado, respecto del poco involucramiento del "principal" en la gestión del "agente", pues su respuesta no obedece a lo que ellos hacen, como supervigiladores de la labor del "agente", sino que más bien se resguardan en lo que puedan hacer otros organismos. Aún así, el $33,3 \%$ de los rectores y casi el $18 \%$ de los miembros de los MCC, sostienen claramente que existe una carencia de control.

Dado que hemos podido constatar que en general la apreciación que existe sobre el sistema de control interno es deficiente, es posible esperar que los mecanismos de control externo funcionen apropiadamente. Los resultados los analizaremos a continuación.

\section{- Control externo}

Es claro que el sistema de educación superior chileno, se enfrenta a grandes retos, es así como ya en el año 1997 el ministro de educación de la época sostenía que el desafío que enfrentan las universidades es no sólo de gestión, finan- 
ciamiento y organización, sino también, de concepto, de identidad y de misión (Arellano, 1997). De esto es posible desprender que el tema del control externo cobra una especial relevancia, pues en general existe una visión crítica en la opinión pública, respecto de la carencia de mecanismos reguladores del sistema.

La realidad descrita previamente, se confirma, a la luz de los resultados obtenidos en la encuesta aplicada. De los datos que aparecen en el Gráfico № 5 , se puede relevar el hecho que de acuerdo a la percepción de los encuestados sólo el Ministerio de Educación (MINEDUC), ejerce un control medio, hecho que tampoco es ampliamente compartido por los encuestados (este porcentaje no llega la $24 \%$ en el caso de los miembros de los MCC, y de los tres rectores entrevistados, sólo dos están de acuerdo con esta opción).

Otros organismos externos que debieran ejercer un cierto control sobre la educación superior, como es el caso del la Contraloría General de la República, el Servicio Nacional de Protección al Consumidor (SERNAC) o la Inspección del Trabajo, en opinión de los encuestados, prácticamente están al margen de lo que ocurre en las universidades.

A pesar de la evidente realidad que se observa en el gráfico previo, los encuestados asumen una posición bastante conservadora, al momento de responder por la "evaluación general del sistema de control externo", pues ningún encuestado lo consideró "malo", concentrándose las respuestas más bien en la opción "bueno" $(66,7 \%$ de los rectores y 35,3 de los miembros de los MCC) y en la opción intermedia "ni bueno, ni malo" (33,3 en el caso del agente y $58,8 \%$ en el caso del principal).

A la luz de las respuestas entregadas por los encuestados, se hacía imprescindible tener una justificación de esta situación. Al respecto, no deja de llamar la atención las respuestas de los encuestados. Dos de los rectores, simplemente se limitaron a expresar que "estos sistema de control, son comunes en las universidades" y el otro se apoyó en el hecho de que en términos generales "la Contraloría General de la República, nunca ha hecho mayores reparos al sistema de gestión de las universidades" y eso podría estar indicando y respaldando que existe poca preocupación de este organismo gubernamental por el tema universitario. Por su parte, los miembros de los MCC, prácticamente se desentienden de esta situación, pues más del $40 \%$, se limitó a expresar que "no tiene ningún comentario que hacer al respecto"; otro porcentaje importante $(35,3 \%)$, simplemente no justificó lo que había expresado previamente.

Al percatarnos de los niveles mínimos de control, tanto interno como externo, no es de extrañar que más del $29 \%$ de los "principales" (P.28), sostiene que el agente "nunca" o "pocas veces", asumen su responsabilidad por incumplimiento de objetivos. Es más, de los tres rectores, dos estuvieron de acuerdo en expresar que la "mitad de las veces" asumen algún grado de responsabilidad, cuando no se logran las metas, previamente panificadas.

De lo anterior se desprende, que incluso el "control por resultados", tampoco es un instrumento eficiente a la hora de evaluar la gestión de los rectores, dado 


\section{Gráfico 5}

\section{Grado de control de organismos externos en tres universidades chilenas}

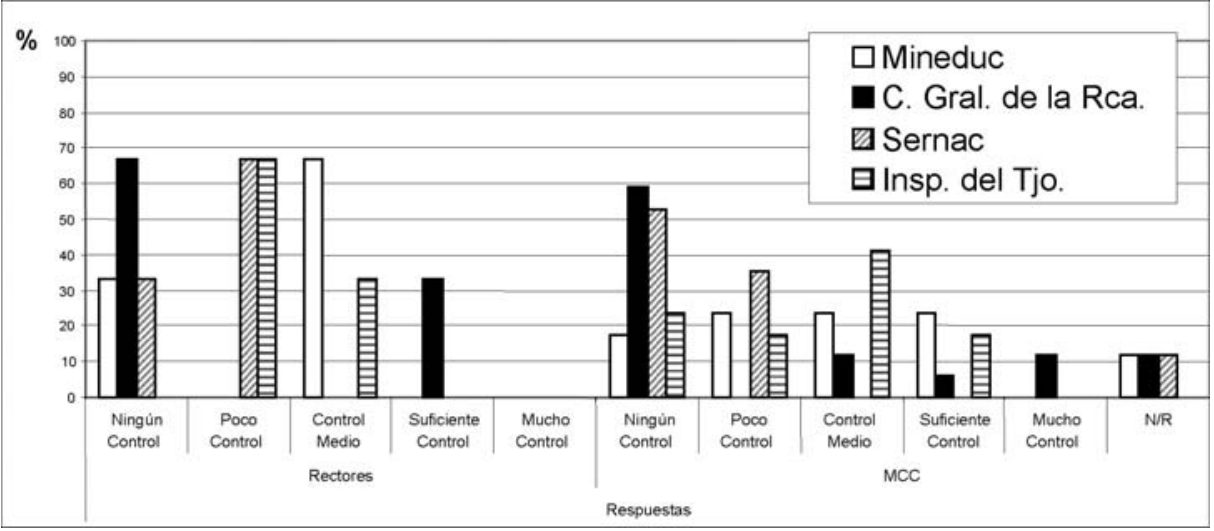

Fuente: Encuesta realizada por el autor.

que un control de esta naturaleza debe traer aparejado un sistema que permita que el "agente" asuma consecuencias, cuando no cumple con las expectativas que tenía el "principal", cuando éste le encargó que actúe en su nombre, en carácter de directivo.

De todos los antecedentes recopilados sobre el tema del control, queda en evidencia, que los mecanismos existentes en el sistema de educación superior, sean internos o externos, son absolutamente insuficientes, si se trata de asegurar un cumplimiento eficiente de objetivos por parte del agente. Es claro que aquí se encuentra, probablemente, uno de los mayores desafíos de la gestión universitaria.

\subsection{Legislación en materia de universidades}

En general se percibe en las opiniones que dan las personas y autoridades del ámbito de la educación, en noticieros, entrevistas, seminarios y artículos de revistas, que existe un alto grado de disconformidad con las normativas que se dictaron a partir de los años 80 , en materia de educación superior. Es por ello, que lograr la sistematización de estas opiniones, de personas que llevan años en el ámbito universitario, no deja de ser relevante. Esto cobra aún mayor sentido, si lo conectamos con la necesidad de lograr ciertos alineamientos de de intereses, pues, en la medida que los objetivos y las percepciones son relativamente comunes, las posibilidades de trabajar mancomunadamente, se torna más propicia, con el consiguiente efecto positivo en la gestión.

En este orden de cosas, cuando se les solicita a los entrevistados, que evalúen en términos generales las actuales normativas en materia de educación superior, el $100 \%$ de los agentes y casi el $60 \%$ de los miembros de los MCC, esti- 
man que son "regulares", es decir, "ni buenas, ni malas"; pero adicionan a su repuestas, en proporciones similares $(66,7 \%$ rector y 52,9 miembros de los MCC), que estas normativas han tenido un efecto en la gestión que llevan a cabo los agentes. Inmediatamente surgen opiniones que no dejan de llamar la atención, pues, a pesar de que la mayoría considera "regulares" las normativas, el $100 \%$ de los encuestados concuerdan en la "necesidad de implementar reformas a las actuales normativas". En esta línea de respuestas, las opiniones apuntan primordialmente a la "reformulación de la Ley Orgánica Constitucional de Enseñanza" $(66,7 \%$ de lo rectores y $41,2 \%$ de los miembros de los MCC). Los otros porcentajes se distribuyen en la necesidad de "regular la oferta y calidad de las instituciones" y la "reformulación del proceso de acreditación". Un porcentaje relativamente menor de los miembros de los $\operatorname{MCC}(17,6)$, sostiene que debieran incorporarse al sistema "mayores mecanismos de control".

De los resultados presentados, es factible adicionar, a modo de reflexión final, que si bien es cierto los encuestados perciben como regulares las actuales normativas en materia de educación superior, todos coinciden en la necesidad de llevar a cabo iniciativas que posibiliten la materialización de reformas en el actual sistema universitario, dado que ello tendría un efecto directo en la gestión de las universidades. En este orden de cosas, los "dardos" apuntan primordialmente a la reformulación de la Ley Orgánica Constitucional de Enseñanza (LOCE), y en menor medida, introducir mecanismos que regulen la oferta y la calidad de los servicios que entregan las instituciones de educación superior.

Probablemente una reforma integral a los actuales marcos regulatorios en materia de educación superior, debieran incorporar además ciertas normativas que aseguren la práctica de un "buen gobierno universitario", estableciendo bases para mejorar sostenidamente la gestión de las universidades.

\section{Conclusiones}

Teniendo la precaución de que los resultados obtenidos se deben tomar con cautela, y conscientes de que estos reflejan la percepción del "agente" y del "principal" de sólo tres universidades, nos atrevemos a esbozar y a presentar comentarios que debiesen ser corroborados, cuando esta investigación exploratoria abarque la totalidad del sistema universitario chileno.

Hecha y remarcada esta aclaración, y tomando como base la información recopilada, es claro que la educación superior chilena se enfrenta a grandes desafíos en lo que a gestión universitaria se refiera. En primera instancia nos atrevemos a plantear, que se deben buscar fórmulas que afiancen el involucramiento de los miembros de los MCC, de tal forma que ellos se incorporen manera protagónica en los procesos de toma de decisiones, haciéndose necesario, una disminución de las "asimetrías de información" percibidas.

Este mismo análisis es válido, cuando se trata de examinar lo que ocurre en la "alineación de intereses", los 
cuales son visiblemente divergentes entre "agente" y "principal". Esta situación, es preocupante, pues en un escenario de esta naturaleza, se puede afectar considerablemente la eficiencia del gobierno universitario, puesto que el alcance de las grandes metas que se plantea una organización, tienen directa dependencia del nivel de concertación que exista con metas específicas, y para ello, el punto de partida debiera ser, manejo de información común e intereses medianamente alineados.

En cuanto a la "eficiencia percibida", ésta fue una variable que en términos generales tiene una positiva valoración en los encuestados, en lo que a eficiencia en la gestión universitaria se refiere. Las percepciones divergentes entre "principal" $y$ "agente", surgen cuando se trata de identificar los "factores críticos de éxito" en la gestión.

El mismo nivel de disensión comentado previamente, se advierte cuando se trata de analizar lo que ocurre con los sistemas de incentivos; dado que lo que piensa el "principal" que motiva al "agente", no necesariamente coincide con lo que realmente incentiva al "directivo". Pero si quedó medianamente claro, que la motivación del "agente" se debe buscar en un manejo apropiado de un "mix retributivo", pues este si genera "alineación de intereses" entre rector y los miembros de los MCC. Pero para que lo mencionado tenga un efecto positivo, en la gestión universitaria, se requiere de una alto nivel de "compromiso", del "principal", quien debiera ser capaz de concordar con el "agente" los mecanismos más apropiados, que posibiliten un comporta- miento del "directivo", acorde a las expectativas que tenga el "principal".

Pero sin duda, que uno de los grandes temas que tiene relación con los "sistemas de control", que a raíz de los resultados proporcionados por las encuestas, y apoyados en información secundaria, es evidente que ellos son insuficientes. Lo demuestran sus débiles sistemas de control interno y la mínima labor contralora de organismos externos. Probablemente esta sea una de las razones, por las cuales los agentes no se sienten presionados mayormente por asumir consecuencias en caso que determinados objetivos no se cumplan.

Pero para que el sistema de control mejore, según la percepción de los encuestados, se debe apuntar a una reformulación de las actuales normativas en materia de educación superior, especialmente en lo relativo a la LOCE y a la calidad de la oferta educativa; pero adicionalmente, estimamos que se deben implementar marcos regulatorios que posibiliten la materialización de un "buen gobierno universitario", el cual debiera sentar las bases para acceder a un mejoramiento sustantivo y sostenido de la gestión universitaria.

A modo de cierre, y con la intención de confirmar la línea de investigación, que se pretende desarrollar, se les consulta a los rectores y los miembros de los MCC, si ellos creen o están de acuerdo con el actual sistema de gobierno universitario existente en Chile. Las respuestas, tal como se aprecia en el Gráfico 6, son concluyentes.

De lo anterior, se puede desprender, que el terreno del gobierno universitario es absolutamente propicio para in- 


\section{Gráfico 6 \\ Grado de acuerdo con el actual sistema de gobierno universitario chileno}

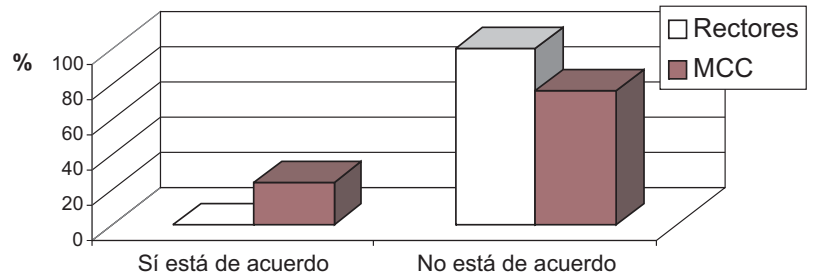

Fuente: Encuesta realizada por el autor.

tervenir con esta u otro tipo de investigaciones. Como ha quedado demostrado en este estudio, de naturaleza "exploratoria”, las avenidas son amplias para poder aportar en el mejoramiento de las relaciones entre rectores y sus máximos cuerpos colegiados, y de paso, mejorar los niveles de eficiencia de la gestión universitaria. El desafío siguiente, será ampliar la investigación a todo el sistema universitario chileno, y quien sabe, a futuro extender este análisis a todo el contexto latinoamericano.

\section{Referencias Bibliográficas}

Armanet, Pilar (2000), Los desafíos de la educación superior chilena en el siglo XXI. Chile: Consejo Superior de Educación: Edición María Eugenia Morales Contreras.

Arruñada, Benito (1990), Economía de la Empresa: Un enfoque contractual. Ariel, Barcelona.

Azofra, Valentín (1999), El consejo de administración como mecanismo de gobierno de la empresa: fundamentos teóricos y evidencia empírica. España: Trabajo de investigación. Departamento de Economía y Adminis- tración de Empresas. Universidad de Valladolid.

Bengoechea, Juan (1996), El gobierno de empresas: características del debate actual. España: Revista Situación. № 3.

Berglöf, Erick (1997), Reforming corporate governance: redirecting the european agenda. Economic Policy, abril.

Brunner, José (2003), Educación superior y desarrollo en el nuevo contexto latinoamericano. Disponible en Internet: http://www.mecesup.cl/difusion/ revista/revista1B.pdf (Accesado en: Noviembre de 2003).

Cuervo-Cazurra, Álvaro (1996), Tres visiones teóricas de las funciones del consejo de administración. España: Revista Situación. № 3.

De la Fuente, Luis (2002), El gobierno corporativo está de moda. Disponible en internet: http://www.riesgoycontrol. Net/archivo/el_gobierno_corporativo_esta_de_moda.php (Accesado en: febrero 2004).

Díaz, Eduardo (2003), Plantean incorporar prácticas de gobierno corporativo en proyectos que buscan dinamizar mercado de valores. Disponible en internet: http://www.cpnradio.com. 
pe/html/2001/11/23/3/41.htm (Accesado en: febrero 2003).

Escobar, Ricardo (2001), Corporate governance in Chile. New Developments OECD Meeting. Argentina.

Fernández, Ana. y Silvia Gómez (1999), El gobierno de la empresa: mecanismos alineadores y supervisores de las actuaciones directivas. España: Revista Española de Financiación y Contabilidad. Extraordinario № 100.

Fundación de Estados Financieros (2002), Estudio para la mejora del gobierno corporativo, la transparencia informativa y los conflictos de interés. Disponible en internet: http://www. ieaf.es/archivos/GobCorporativo.pdf (Accesado en: febrero 07. 2004).

Jensen, Michael. y William Meckling (1976), Teoría de la empresa: La gerencia; costes de agencia y estructura de la propiedad. Apunte proporcionado en la Asignatura Economía Financiera del Programa de Doctorado en Nuevas Tendencias en Dirección de Empresas. Universidad de Valladolid. España.

KPMG (2003), Código de Mejores Prácticas Corporativas, Metas del Gobierno Corporativo. Management Assurance Services, Finsterbusch Pickennhayn Sibille.

KPMG (2002), Diez Pasos para Mejorar el Gobierno Corporativo en su Organización, tomado del Estudio "Corporate Governance; The New Estrataegic Imperative", Producido por la Unidad de Inteligencia de The Economist, con el Patrocinio de la KPMG, Panamá.

Le Fort, Fernando y Eduardo Walker (2001), Fundamentos conceptuales de la ley de Opas: gobierno corporativo, protección a accionistas minoritarios y tomas de control. Superintendencia de Valores y Seguros de Chile. Chile.
Martín, Natalia y Ana Gutiérrez (2001), Relaciones de agencia en el sector farmacéutico español: marco institucional y decisiones estratégicas. España: Documentos de trabajo Nuevas Tendencias en Dirección de Empresa. Departamento de Economía y Administración de Empresas. Universidad de Valladolid.

Mathiesen, Henrik (2002), Managerial Ownership and Financial Performance, Ph.D. dissertation, series 18.2002, Copenhagen Business School, Denmark. Download summary.

Maw, Nigel (1994), Maw on Corporate Governance, Editorial by Alison Alsbury. Dartmouth Publishing Company Limited.

Milgrom, Paul y John Roberts (1993), Economía, Organización y Gestión de la Empresa. España: Editorial Ariel S.A.

Ministerio de Educación de Chile (2003), Estadísticas institucionales. Disponible en Internet: http://www.mineduc.cl/ (Accesado en: Octubre, 2003)

Ministerio de Educación de Chile (1997), Estatutos de la Universidad Autónoma del Sur.

Nilakant, Venkataraman (1994), Agency theory and uncertainty in organizations: an evaluation. Organization studies. Vol. 15.

Novy, Andreas (2004), Economía, política internacional: Con ejemplos de América Latina. Disponible en Internet: http://www.lateinamerika-studien.at/ content/wirtschaft/ipoesp/ipoesp2087.html (Accesado en: Octubre, 2004)

OECD (1999), OECD Principles of Corporate Governance, April 19. Download directly from OECD's site.

Parasi, Franco; Rodrigo Godoy y Antonino Parasi (2000), Gobierno corporativo: evidencia reciente. Current versión. 
Pérez, M. y Moza. F (2000), Una perspectiva dual para la gestión de los recursos humanos: ¿optimizar recursos o reducir costes contractuales? España: Revista de Dirección y Organización.

Salas, Vicente (2002), El gobierno de la empresa. España: Caja de ahorros y pensiones La Caixa.

Shleifer, Andrei, y Robert W. Vishny (1997), A survey of corporate governance. The Journal of Finance, 52.

Suárez, Andrés (1997), Economía y finanzas. Desde la teoría de los mercados a la teoría de la empresa. Disponible en Internet: http://www.ucm.es/info/ assuarez/art1.pdf (Accesado en: Octubre de 2004).
Universidad Austral de Chile (1986), Estatus de la Universidad Austral de Chile. Chile. N.

Universidad De Los Lagos (1994), Estatus de la Universidad De Los Lagos de Chile.

Zingales, Luigi y Rajan, R. (1998), The governance of the new enterprise. Estados Unidos: Working Paper, University of Chicago. 